\title{
The hydrological characterisation and water budget of a South African rehabilitated headwater wetland system
}

\author{
ES Riddell*, C Everson, A Clulow and M Mengistu \\ Centre for Water Resources Research, School of Agriculture, Earth and Environmental Science, University of KwaZulu-Natal, \\ Private Bag X01, Scottsville, 3209, South Africa
}

\begin{abstract}
This paper presents a synopsis of the findings of a valley bottom wetland monitoring study in which dominant hydrological processes maintaining the system are quantitatively defined. The Craigieburn-Manalana is a wetland subjected to technical rehabilitation, at the headwaters of the Sand River in the lowveld savanna region of South Africa.

Findings include the identification of a rapid water delivery mechanism from the surrounding hillslopes to the wetland following a threshold-exceeding precipitation event, when hillslope-toe soil matric potential is close to 0 , leading to a raising of the wetland water table by $>0.7 \mathrm{~m}$ within $3 \mathrm{~h}$. A summary of quantified fluxes and associated water budget of the wetland and its contributing catchment is developed. It is revealed that this wetland does not necessarily conform to the typical assumptions that wetlands augment low flows. Surface layer scintillometry shows actual wetland evapotranspiration to dominate the water budget during the dry season $(2.3-3.5 \mathrm{~mm} / \mathrm{d})$ compared to its contributing catchment $(0.9-2.2 \mathrm{~mm} / \mathrm{d})$, whilst stream discharge had ceased. Hydrograph separation, based on stable isotopes $\left({ }^{18} \mathrm{O}\right)$, revealed that the wetland does not attenuate peak flows during the summer rains when the wetlands soil moisture deficit is close to 0 , since more than $66 \%$ of stream discharge comprised event water. These results are discussed within the context of current hydrological understanding of southern African headwater wetlands, such as dambos.
\end{abstract}

Keywords: hillslope processes, hydro-geomorphology, water budget, dambos, rehabilitation, wetlands

\section{Introduction}

There is a general dearth of knowledge of the hydrology of wetland systems in Africa, and this has duly been noted for Southern Africa also (Grenfell et al., 2005). Where hydrological studies have been undertaken on wetlands in the region, they are constrained by the heterogeneous geomorphic templates of the landscape, which cause each wetland to seemingly operate in different ways; this precludes the development of a unifying wetland hydrological process framework. The southern African sub-continent differs vastly from the temperate northern continents in a number of ways: firstly it has an ancient and relatively tectonically stable land-mass which sits at a high mean elevation; second, the region escaped recent glaciation episodes that have shaped the landscapes in other regions; third, southern Africa has significantly lower average rainfall than other continents coupled with a high evapotranspiration demand. These factors combine to limit the extent of the majority of wetlands in the region to stream networks. This means that general underscoring principles of wetland management, gathered now quite comprehensively in the temperate regions of the world, are unlikely to be suitably applied to the wetlands of southern Africa (Ellery et al., 2008). Nevertheless, as the systems of southern Africa are studied in more detail, it is hoped that a sphere of overarching principles will emerge by which the sustainable management of their processes and resources may be secured in the future. This issue is of tantamount importance given that great emphasis is being placed on wetland rehabilitation, particularly in South Africa, through poverty relief strategies. This is a laudable undertaking for

\footnotetext{
* To whom all correspondence should be addressed.

푱 +27-723371274; e-mail: edriddell@gmail.com

Received 1 February 2012; accepted in revised form 15 November 2012.
}

political, social and environmental reasons; however the environmental component of this objective may well be undermined by unsatisfactory understanding of the hydro-geomorphic controls and fluxes that would otherwise characterise these wetlands in a natural state, possibly leading to inappropriate rehabilitation measures (Tooth and McCarthy, 2007).

This paper summarises the hydrology of a riparian headwater wetland in the semi-arid north east of South Africa, the degradation of which through significant gully erosion is similarly experienced in other wetlands in the area. This degradation is assumed to be a compound effect of, firstly, the local geological and climatic conditions - i.e., steep granitic geology and intense rainfall due to being located close to the northern Drakensberg Escarpment. Secondly, historical political legacies have asserted a significant anthropogenic pressure on this landscape through forced resettlement and consequent expansion of population pressure on this sensitive region of the South African lowveld. The lowveld is a South African bioregion characterised by woody savanna dominated by Combretrum and Terminalia vegetation (Mucina and Rutherford, 2006). A major pressure in this landscape is the extensive use of the valley bottom wetlands for subsistence agriculture. An extensive assessment of the causal mechanisms of wetland degradation in the Sand River headwaters is provided by Pollard et al. (2006) and the assumption outlined is that this degradation, along with streamflow reduction by commercial forestry, has contributed to the loss of baseflow in the Sand River system. Essentially these conditions have fostered a switch in the Sand River from being a major perennial tributary of the Sabie River to one that is now dominated largely by a seasonal flow regime. The Sand River's flow regime and issues related to its deterioration are discussed in Pollard et al. (2011, 2012). Pollard et al. (2006) reports on an exploratory modelling exercise using ACRU (Schulze, 1995) at a variety of scales, which supported the notion that loss of wetland extent in the headwaters of the Sand 
River catchment had significant detrimental effects on streamflow processes at the broader catchment scale.

\section{Headwater wetland hydrology}

To date, in the subcontinent most attention has been paid to the process definition of a certain type of wetland which lies at the headwaters of large river systems and is usually termed vlei (South Africa) or dambo (Zimbabwe/Zambia). Early works generated the belief that these systems are important for streamflow regulation processes in terms of flood attenuation and low flow augmentation, in essence by acting as 'sponges' absorbing water during the rains with sustained release during the dry season (e.g. Balek and Perry, 1972). Recent work has however challenged this assumption showing that such systems do not always attenuate flood flow or augment dry season baseflows (Von der Heyden and New, 2003; McCartney, 2000; Bullock, 1992). Meanwhile these systems retain the potential to be, and often are, used as an agricultural and grazing resource within the region, due to their moisture-holding properties particularly in the dry season.

Von der Heyden (2004) produced a comprehensive review based on the abovementioned works, among others, extrapolating the common hydrological processes that were experienced in different headwater wetland studies and critiquing them against various proposed models of dambo hydrological and hydrogeological function from the literature. It was however acknowledged that, due to their widespread distribution and hence high variability in geo- and meteorological characteristics, no unifying model could be prescribed for estimating the hydrological responses of dambos. Nevertheless an attempt was made to link estimated hydrological response to a set of catchment characteristics based on: size of the catchment; size of the dambo; catchment vegetation; rainfall regime; and sand to silt and clay fraction of the interfluve soil.

This yielded several hypotheses of dambo hydrological responses (Von der Heyden, 2004) including: the dominant source of water to the dambo is derived from direct rainfall; interfluve vegetation characteristics are the primary determinants of the relationship between dambo and interfluve evapotranspiration (ET) losses; duration of dry season flow from dambos is directly proportional to the catchment-dambo surface area ratio, as well as the sand to clay-silt ratio within the interfluve soils; volume of dry season flow from dambos is directly proportional to the catchment-dambo surface area ratio; attenuation of stormflow is a function of both the catchment-dambo surface area ratio and the intensity of the rainfall event as well as the sum of current seasonal precipitation.

Furthermore, 3 conceptual models of dambos were presented by Von der Heyden (2004), based on the literature describing the hydrogeological controls on these systems. All of these models acknowledge the presence of a low permeability layer close to the dambo surface that impedes the vertical flow of water into the dambo, and which has evident consequences on the hydrological processes within these systems.

\section{Sand River wetlands: typically dambos? Consequences for rehabilitation?}

The main objective for instrumenting the CraigieburnManalana catchment for hydrological process definition was to examine the response of wetland hydrology to technical rehabilitation of large erosion gullies and to determine the broader hydrological context of the system (described in Riddell et al., 2012). The findings presented here are discussed in relation to components of the Craigieburn-Manalana wetlands water budget in the context of current understanding of dambo hydrology.

\section{Methods}

\section{Study site information}

The Craigieburn-Manalana catchment was developed as a hydrological research catchment in 2005, in response to the technical rehabilitation of wetland erosion gullies. It lies in the sub-humid fringe of the semi-arid lowveld and has a mean annual precipitation of $1075 \mathrm{~mm}$ per annum (South African Weather Service, Wales 0594819 rain gauge 1904-2000) and a similar rate of potential evapotranspiration.

The catchment lies on the granitic geology of the basement complex and is intersected by doleritic dykes, as a consequence the catchment is dominated by sandy soils ( $76 \%$ of catchment), particularly in the valley bottom, except for doleritic areas which yield fine clays ( $24 \%$ of catchment).

It was postulated prior to rehabilitation (2004-05) that moisture is retained within this sandy and rather conductive wetland substrate by zones of finer sediment, or, in other words vertical clay subterranean walls, which have informally been termed 'clay plugs'. This potential hydro-geomorphic structure was originally identified during the first season of monitoring through electrical resistivity imaging (ERI) and was thought to exert a considerable control on the sub-surface hydraulic processes, by essentially buffering sub-surface throughflows, due to its expected lower hydraulic conductivity than the surrounding sandy wetland substrate. Further determination of this hydrogeomorphic control is discussed at length by Riddell et al. (2010), revealing that the clay plug is now threatened by the further upstream retreat of the erosion gully (Riddell et al., 2012). The conclusions are that loss of these clay plugs would lead to the loss of a sub-surface control exerting hydrodynamic protection of the wetland upstream of it. These surveys also revealed that the wetland is underlain at depth by clays and that the overburden is dominated by coarse sands.

Land use in the catchment is dominated by peri-urban rural settlement, free-roaming grazing and extensive use of the valley bottom wetlands, particularly for the cultivation of madumbes, Colocasia esculenta, during the wet season. Typically, during the dry season cultivation ceases and both agricultural and indigenous wetland vegetation is burned on plots, whilst fallow stands of indigenous vegetation may remain. Wetland plots consist of steep raised beds and deep drainage furrows which run parallel to the direction of catchment runoff. There is also extensive gully erosion in the wetland itself as well as on the catchment interfluves. The wetland was almost completely converted to the ridge and furrow system. However at the time of analysis this had been left fallow for 4 years and was dominated by re-emerging reed beds (Phragmites mauritianus). The upland interfluve consists of mixed seasonal shrub and grassland with Mabola plum (Parinari curatellifolia). The wetland and interfluve represent $4 \%$ and $96 \%$ of the 23.3 ha area of the catchment upstream of the weir, respectively.

\section{Hydrology}

The Craigieburn-Manalana catchment was instrumented with hydrometric apparatus during the latter half of winter 2005 


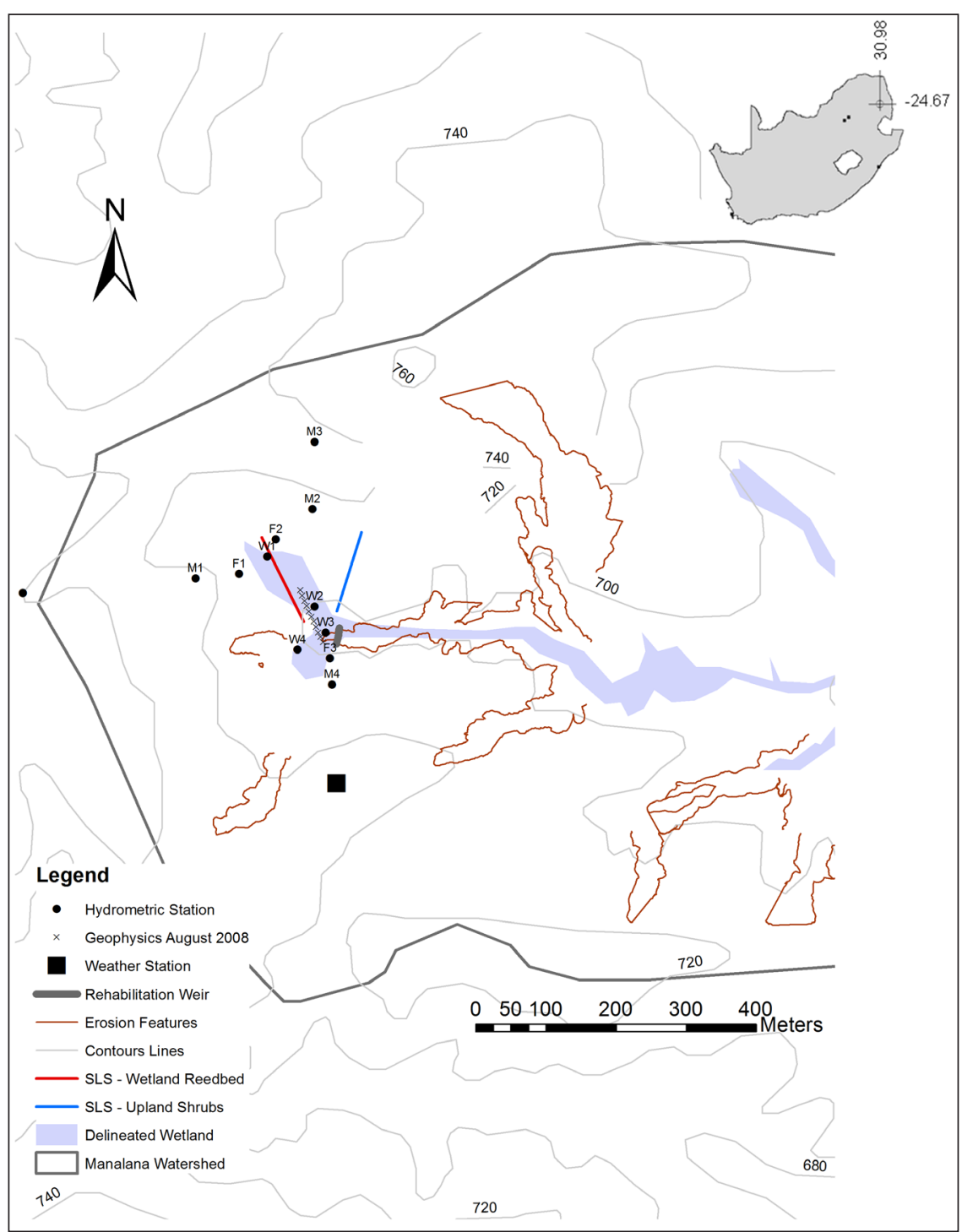

Figure 1

The Craigieburn-Manalana wetland with locations of hydrometric instrumentation and measurements and location within South Africa ( $M, F$ and W denote mid-slope [steep, transportational], foot-slope [shallow, depositional] and valley bottom [alluvial] wetland positions respectively)

(August-October), along 3 transects perpendicular to the catchment ( 2 of which are shown in Fig. 1). Along these transects hydrometric stations were positioned, fitted with 3-channel soil moisture tensiometer sensors, typically at 300,600 and 2000 $\mathrm{mm}$ depths alongside nested groundwater level piezometers (typically at 2000,4000 and $6000 \mathrm{~mm}$ depths in the wetland, and at $2000 \mathrm{~mm}$ and $6000 \mathrm{~mm}$ depths on the footslopes).

Piezometers were manually read using a dip-meter every $2-3$ days and in some instances fitted with pressure transducers. These data were collected using $\mathrm{HOBO}^{\mathrm{TM}}$ data loggers using a University of KwaZulu-Natal timing board system. This allowed continuous 12-min time-step recording of soil moisture tension and groundwater levels at hillslope and wetland positions.

Daily wetland lateral groundwater flows were estimated for periods of the wet summer and dry winter by determining the hydraulic gradient and saturated hydraulic conductivity using the bail method of Bouwer and Rice (1976) between piezometer nests according to Eq. (1):
$Q^{d}=\sum i K$ where $i=\frac{h 1-h 2}{D}$

where:

$i$ is the hydraulic gradient

(dimensionless)

$h 1$ and $h 2$ is piezometric head at $\mathrm{W} 1$ and $\mathrm{W} 2$ respectively $(\mathrm{mm})$

$D$ is the distance between piezometers (mm)

$K$ is the saturated hydraulic conductivity in $\mathrm{mm} / \mathrm{h}$

$Q^{d}$ is the daily average discharge (mm)

The catchment was also fitted with a full meteorological Campbell Scientific ${ }^{\mathrm{TM}}$ weather station for estimation of potential evapotranspiration (pET) using the Penman-Monteith equation (Allen et al., 1998). This station was also fitted with a Texas Instruments $^{\mathrm{TM}}$ TE525MM rain gauge.

A concrete buttress-weir was initially installed for the purposes of wetland rehabilitation between December 2006 and March 2007; however, due to unforeseen erosion problems it only became effective following remedial actions prior to the 2008-09 season (Riddell et al., 2012). Streamflows were recorded during the 2008-09 wet season at the outlet of the intact portion of the wetland. This followed the completion of a weir which included a compound $90^{\circ}$ v-notch (low flows) and rectangular section (high flows). These were rated using the methods of the US Department of the Interior (2001). This used a submersible float gauge with Campbell Scientific ${ }^{\mathrm{TM}}$ CS410 shaft encoder attached to CR200 data-logger. An ISCO ${ }^{\text {TM }} 24$ bottle $(500 \mathrm{~m} \ell)$ sampler was also integrated with this logging system to enable

the collection of water samples for in-stream isotope species analysis $\left(\mathrm{O}^{18}\right.$ - oxygen-18 and $\mathrm{H}^{2}$ - deuterium) at prescribed flow depths, using a program to determine cumulative flow indices to trigger sampling in both high and low flow periods (for further details consult Riddell, 2011). Isotope analysis was performed using a Los Gatos Research (LGR) DT-100 Liquid Water Isotope Laser Analyser at the University of KwaZuluNatal. Two-component hydrograph separation was achieved using the method described by Uhlenbrook and Hoeg (2003) in the form of Eq. (2):

$$
Q_{E}=Q_{T} \frac{c_{T}^{18} O-c_{P}^{18} O}{c_{E}^{18}-c_{P}^{18} O}
$$

where:

$Q_{E}$ is the total contribution of event (rainfall) water to stream discharge

$Q_{T}$ is the total volume of discharge

$c_{T}$ is the total isotopic composition of discharge water $c_{P}$ is the isotopic composition of pre-event water 
$c_{E}$ is the isotopic composition of event water

${ }^{18} \mathrm{O}$ reflects the stable isotope used - in this case oxygen- 18 .

In addition, during the 2008-09 season the actual quantification of evapotranspiration losses from vegetation types in the Craigieburn-Manalana catchment took place using OEBMS1 Scintec $^{\mathrm{TM}}$ surface layer scintillometers (SLS). These provide the means to determine the sensible heat flux component of the surface energy balance, derived from atmospheric turbulence using the phenomenon of optical scintillation of infrared radiation (Savage, 2009). Two SLS recorded the sensible heat flux over $100 \mathrm{~m}$ transects in the wetland and uplands, as shown in Fig. 1, during both the winter dry season (28 August 03 September 2008) and summer wet season (28 January 03 February 2009).

The monthly water budget was calculated for the headwater catchment, assuming no upstream surface discharge into the system, according to:

$$
\Delta S=P_{t}-p E T-Q-\left(G_{i}-G_{o}\right)
$$

where:

$\Delta S$ is the total monthly change in storage $(\mathrm{mm})$

$p E T$ is the monthly actual evapotranspiration ( $\mathrm{mm}$ )

$Q$ is the monthly surface discharge at the catchment outlet $(\mathrm{mm})$

$G i$ and $G o$ are groundwater inflows and outflow respectively

During actual evapotranspiration quantification daily upland and wetland water budgets were calculated according to:

$$
\begin{aligned}
& \Delta S_{u}=P_{t}-a E T_{u}-\left(G_{i}-G_{o}\right) \\
& \Delta S_{w}=P_{t}-a E T_{w}-Q-\left(G_{i}-G_{o}\right)
\end{aligned}
$$

where:

$\Delta S$ is the daily change in storage ( $\mathrm{mm})$

$u$ is the upland

$w$ is the wetland

$P_{t}$ is total daily precipitation for the whole catchment $(\mathrm{mm})$

$a E T$ is the daily actual evapotranspiration $(\mathrm{mm})$

$Q$ is the daily discharge at the catchment outlet (mm)

$A$ is the contributing area of the catchment $\left(\mathrm{km}^{2}\right)$

Due to the fact that the deeper footslope piezometers remained dry during the course of the study we made the assumption that groundwater inflow and outflow to the catchment is zero. Similarly no direct deep groundwater flow (as opposed to shallow lateral subsurface flows) is estimated to occur from the interfluve into the wetland.

\section{Results}

This section presents results relating to various components of the wetland water budget.

\section{Inflow mechanisms}

The Craigieburn-Manalana catchment is characterised by rainfall that can often be quite intense as well as having a relatively high inter-annual variability; this is summarised for the total period of monitoring between 2005 and 2009 in Table 1 .

During the course of monitoring it was noted that the soil moisture regime of the catchment follows the distribution of

\begin{tabular}{|l|l|}
\hline \multicolumn{2}{|c|}{$\begin{array}{c}\text { Table 1 } \\
\text { Summary precipitation information for } \\
\text { the Craigieburn-Manalana catchment } \\
\text { (hydrological years in eastern South Africa } \\
\text { run from October-September inclusive) }\end{array}$} \\
\hline Hydrological year & Annual precipitation (mm) \\
\hline $2005-06^{*}$ & 1771.9 \\
\hline $2006-07$ & 809.6 \\
\hline $2007-08$ & 817 \\
\hline $2008-09$ & 1444.9 \\
\hline
\end{tabular}

Mean (2006-09) 15-min rainfall intensity $2.59 \mathrm{~mm} / \mathrm{h}$

Std. dev. $1.4 \mathrm{~mm} / \mathrm{h}$

Peak $85.2 \mathrm{~mm} / \mathrm{h}$

${ }^{*}$ Full record from nearby $(4.6 \mathrm{~km})$ Hebron Forestry

Estate

seasonal rainfall, as would be expected, such that the soils are dry during winter and wet during summer. However noticeable differences were observed between the soils of the two dominant geologies of the catchment (see Riddell et al., 2010), as shown in Fig. 2a. Firstly, the shallow but coarse-grained hillslope soils on granite, of the Leptosol form (FAO, 1998) were characterised by rapid fluctuations in soil moisture tension in the shallow soils $(0-600 \mathrm{~mm})$ due to infiltrating rain water, whilst deeper soils remained largely dry except under exceptional rainfall conditions where saturated vertical flow filled cracks and voids in these weathering horizons. (The saw-tooth appearance of the matric pressure at 300 and 600 $\mathrm{mm}$ depth is as result of an in-house exponential calibration function of the particular sensor at this location, Watermark ${ }^{\mathrm{TM}}$ sensors). Secondly, the deep fine-grained soils of Regosol form (FAO, 1998), derived from the doleritic hillslopes, were characterised by more moderate wet-drying cycles and were freely drained, noted by the more apparent changes in soil moisture tension in the deeper horizons, thus contrasting with the granitic soils.

Whilst the two different dominant geologies showed different hydrological responses, in each of the four successive years of monitoring it was recorded that a threshold-exceeding soil moisture response is initiated at the hillslope toe soils of the Regosol form (FAO, 1998) following a large rainfall event, usually when the catchment was close to saturation. This mechanism that follows the reaching of a certain antecedent soil moisture status and a trigger rainfall event induces a rapid delivery of water to the valley bottom wetland, with a nearinstantaneous elevation in the wetland phreatic surface. This behaviour is shown for an event during early January 2006 in Fig. 2b, whereupon there was a significant drop in capillary pressure head in the deep $2000 \mathrm{~mm}$ tensiometer, located in a clay-rich G-horizon using the terminology of the South African classification system (Soil Classification Working Group, 1991). Consequently, one then observes a similar response in the $2000 \mathrm{~mm}$ tensiometer in the wetland soils, and rapid elevation of the groundwater level as recorded by the corresponding piezometer. A hypothesis to explain this phenomenon may be that soils with dual-porosity (macro-pore) properties occur at these hillslope toe positions. Upon reaching a certain antecedent moisture content macro-pores become conduits for significant sub-surface water movement from the hillslope to the wetland

During the first year of monitoring of wetland hydrodynamics (piezometric surface fluctuations), it was noted that a sequence of vertical recharge processes existed, from the surface to the shallow subsurface overlying deep recharging piezometric surfaces in the wetland. These details are provided 

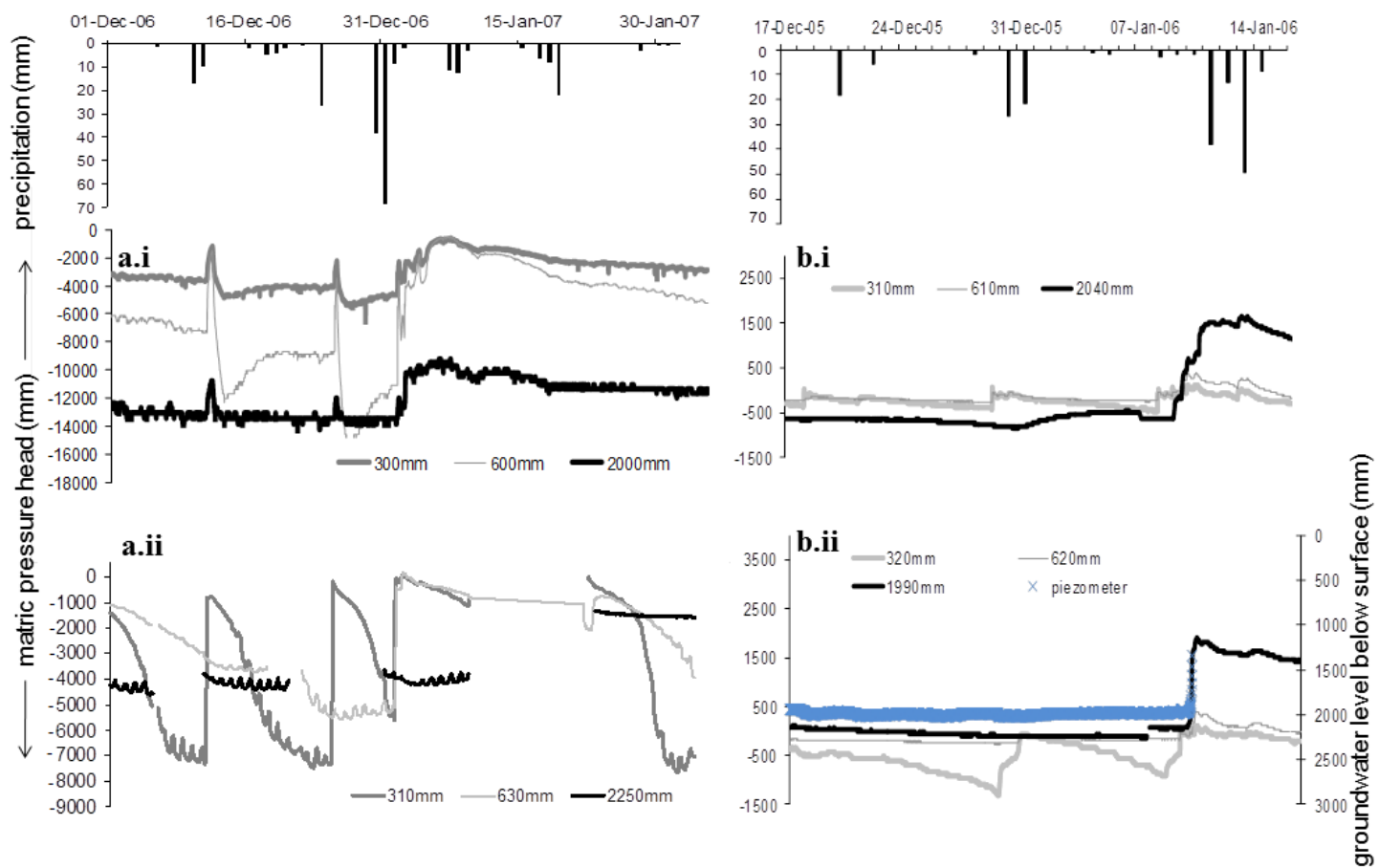

Figure 2

Typical flashy granite hillslope soil moisture response observed at M1 (a.i); typical moderate soil moisture response on doleritic hillslope observed at M2 (a.ii); rapid drop in soil moisture tension at $2000 \mathrm{~mm}$ in G-horizon of hillslope toe (Kroonstad) soils observed at F1 (b.i); consequent drop in soil moisture tension at $2000 \mathrm{~mm}$ in the wetland and rapid elevation of wetland water table observed at W1 (b.ii)

in Riddell et al. (2012), in which stratification in the vertical recharge processes in the shallow sub-surface of the wetland is attributed to the occurrence of narrow clay aquicludes in an otherwise sandy soil matrix. These are a horizontal feature of the system distinct from the vertical clay plugs described previously. Furthermore, it became apparent that certain artesian conditions may also be manifested in this system, particularly at the height of the rains, when shallow piezometers often reflected lower phreatic heads than deeper piezometers at W2 and W3. Whilst this reflected the hydrodynamics for intact regions of the wetland, this was not so for areas in close proximity to the erosion headcut. Furthermore, it had been observed that water table fluctuations at these headcut locations contrasted strongly with other regions of this wetland and that there also appeared to be a discernible hydraulic drawdown at these locations due to the unimpeded drainage through the erosion gully (Riddell et al., 2007). Following the initial installation of the buttress weir in the 2006-07 season, the reintroduction of an artesian piezometric surface was revealed adjacent to the erosion headcut. This implied a positive response to the system, given that it would have been expected that this type of artesian hydrodynamic behaviour would exist throughout this wetland.

\section{Outflows and water budget}

Since the technical rehabilitation of the Craigieburn-Manalana wetland was only fully implemented during the 2008-09 season, as a result of unanticipated failures of the rehabilitation structure, discharges out of the wetland could only be measured during this, most recent, season of this study. Deep upwelling groundwater movement into, passing through (laterally), and out of the wetland was assumed to be a negligible component of the water budget, based on the estimate obtained from piezometer well readings at W1 and W2 within the deeper clays underlying the wetland; estimates for the dry winter period were $\sim 2.1 \times 10^{-3} \mathrm{~mm} / \mathrm{month}$ and during the wet summer $5.4 \times 10^{-3} \mathrm{~mm} / \mathrm{month}$. The component fluxes of incoming and outgoing water to the catchment mass balance on a monthly basis are depicted in Fig. 3. Here the highly seasonal precipitation $(\mathrm{P})$ and runoff $(\mathrm{Q})$ may be observed, resulting in high precipitation and runoff during summer, i.e. November to March, and in no flows with minimal precipitation in winter (May onwards). Consequently, we note that potential evapotranspiration ( $\mathrm{pET}$ ) represents a net loss of water from the system in winter, assuming of course that actual ET approaches or is equal to $\mathrm{pET}$, and conversely there is a net gain in water in summer due to precipitation. However Fig. 3 reveals an interesting hydrological effect of the catchment - when the outgoing runoff is expressed as a percentage of the incoming precipitation, it is evident that the percentage of rainfall that becomes runoff is minor during October and November, at $<5 \%$. This is to be expected since the catchment begins to saturate. From December to February the percentage of runoff generated ranges between $20 \%$ and $25 \%$; despite the very heavy rains of January this is not seen to yield a significant conversion to runoff. This may well be attributable to an increase in catchment hydraulic roughness resulting from heightened biomass production of emergent wetland (and upland) vegetation at the height of summer, which in itself will enhance the actual evapotranspiration component of the catchment water budget.

Meanwhile, Fig. 4 reveals a two-component hydrograph separation for an event of late December 2008. Using stable isotopes of oxygen-18 revealed that a significant proportion of the stormwater runoff comprises event water (i.e. rainfall collected during the event of 28-29 December 2008) rather than pre-event water ( 1 sample taken in a ponded area adjacent to a furrow stream inlet upstream of the weir on 12 December 

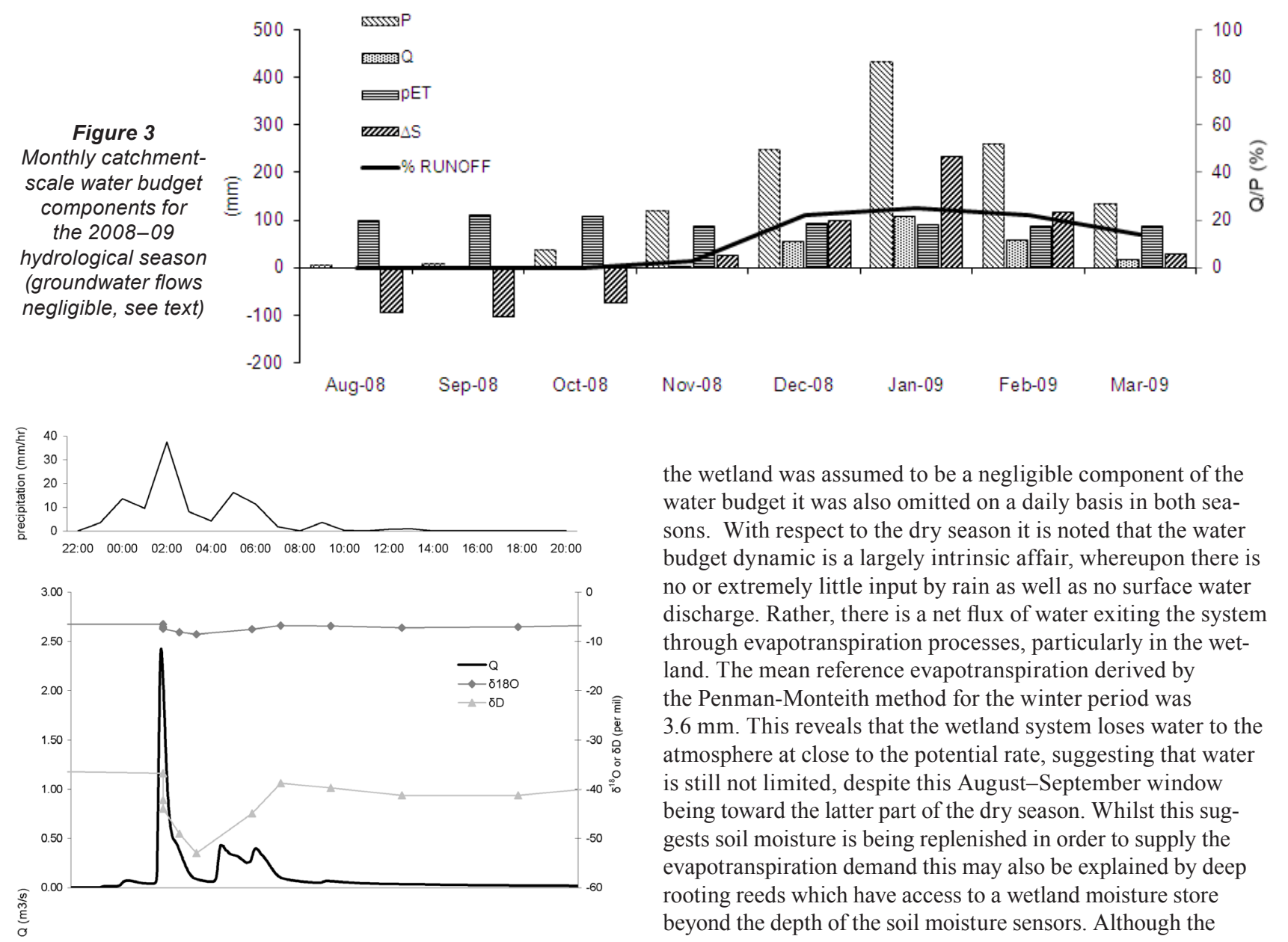

the wetland was assumed to be a negligible component of the water budget it was also omitted on a daily basis in both seasons. With respect to the dry season it is noted that the water budget dynamic is a largely intrinsic affair, whereupon there is no or extremely little input by rain as well as no surface water discharge. Rather, there is a net flux of water exiting the system through evapotranspiration processes, particularly in the wetland. The mean reference evapotranspiration derived by the Penman-Monteith method for the winter period was $3.6 \mathrm{~mm}$. This reveals that the wetland system loses water to the atmosphere at close to the potential rate, suggesting that water is still not limited, despite this August-September window being toward the latter part of the dry season. Whilst this suggests soil moisture is being replenished in order to supply the evapotranspiration demand this may also be explained by deep rooting reeds which have access to a wetland moisture store beyond the depth of the soil moisture sensors. Although the actual evapotranspiration in the wetland is below the potential rate, this suggests that water availability had become limited in the wetland also. Meanwhile the interfluve area does not lose water close to the potential rate, suggesting that water is significantly more limited in this area of the catchment. During the wet season, however, when mean reference evapotranspiration was $3.4 \mathrm{~mm}$, the observed water use on the interfluve and the wetland occurs at or above the potential rate. This suggests that evapotranspiration is enhanced by the full use of plant available water by both aquatic and terrestrial vegetation during the wet season. Significantly, therefore, the seasonal balance in water use at the catchment scale is dominated by activation of water use by vegetation on the interfluve, which represents a far greater proportion of the catchment surface area. The summer season also sees the far greater role of rainfall and surface discharge in controlling the water balance, facilitating a significantly large change in storage, which is generally recharging, contrasting sharply with the depleting storage of the dry season.

Figure 5 shows the difference in isotopic ratios for shallow piezometers in the Craigieburn-Manalana wetland compared to local groundwater boreholes, during February 2008. One notes the large difference in signatures between the groundwater cluster and the shallow piezometers at $2000 \mathrm{~mm}$, suggesting (not conclusively) that these waters are not connected. Meanwhile the isotopic ratios for deeper piezometers shows a closer association in signatures between 2 borehole samples and 2 deep piezometers, W1 and W2, suggesting (not conclusively) that these waters are in contact. This also suggests that the wetland sub-surface underlying the clay aquiclude is in contact with the regional groundwater table but not with the shallow waters above the clay aquiclude. Meanwhile the deep 


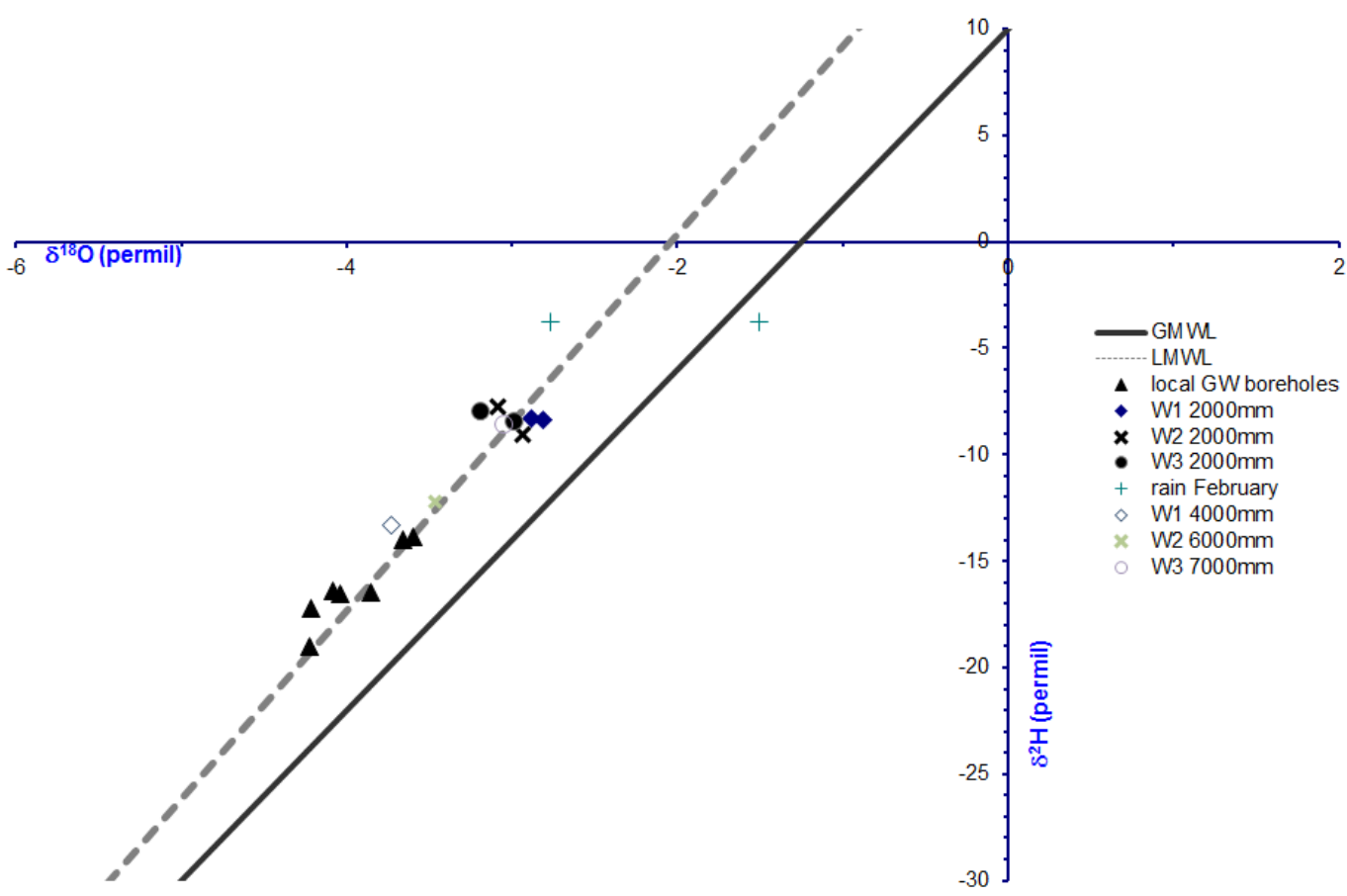

Figure 5

Stable isotope $\left(\delta^{18} \mathrm{O} /\right.$ $\left.\delta^{2} H\right)$ compositions for shallow piezometers against local groundwater boreholes in February 2008

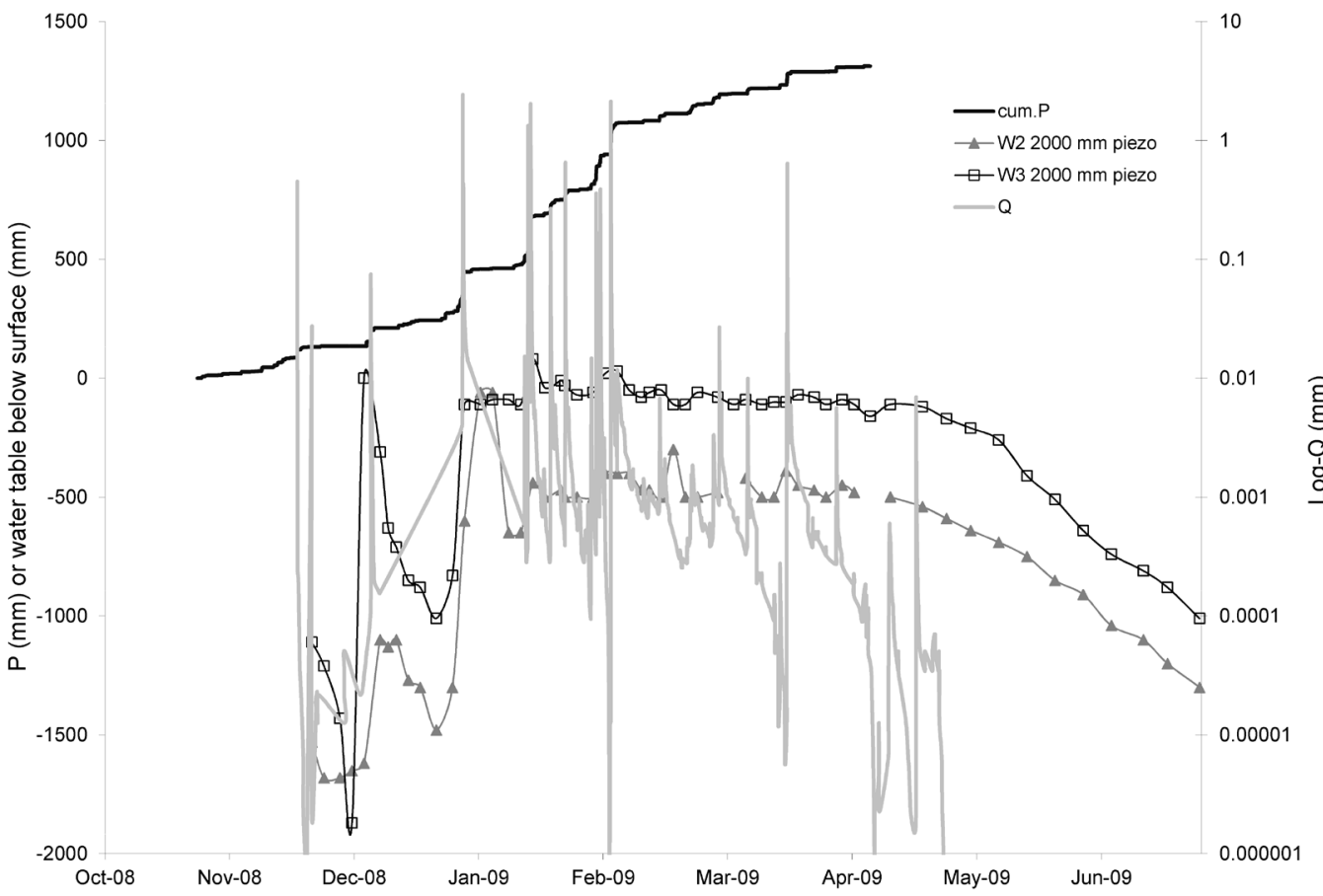

Figure 6

Plot of stream discharge (Q) for the 2008-09 hydrological year, against cumulative rain $(P)$ and shallow piezometer reading at W2 and W3

piezometer at $\mathrm{W} 3$ has a similar isotope ratio to the shallower piezometers suggesting that the installed weir may have facilitated a connection of shallow to deeper waters (downstream of the clay plug).

In order to identify streamflow and shallow sub-surface water connectivity in this wetland Fig. 6 displays the discharge versus shallow piezometer depths during 2008-09. Soon after the cessation of summer rains in mid-April 2009, streamflow stops by 26 April completely and the shallow water tables adjacent to the wetland outlet then begin to decline; however, these are still reasonably shallow and have probably just dropped into the clay aquitard (see Riddell et al., 2010), but not through it, at this time.

\section{Discussion}

\section{In the context of headwater wetland hydrology}

Given the key findings outlined for the Craigieburn-Manalana catchment, and given the context of headwater wetland hydrology in the southern African region, are there any parallels to be drawn between this and other studies? In addition what may this tell us about the effects of technical rehabilitation of the wetlands of the Sand River, for impacts on both intrinsic properties and downstream processes?

Using the Craigieburn-Manalana wetland as an example of the typical wetland setting in the Sand River headwaters, 


\begin{tabular}{|c|c|c|c|c|c|c|c|}
\hline \multicolumn{8}{|c|}{$\begin{array}{l}\text { Table } 2 \\
\text { Daily water budget for the Craigieburn-Manalana wetland for days on which evapotranspiration was quantified } \\
\text { using energy balance techniques (gaps in data on } 31 \text { August } 2008 \text { and } 31 \text { January } 2009 \text { for the upland site are } \\
\text { due to SLS failures). }\end{array}$} \\
\hline \multirow{2}{*}{$\begin{array}{l}\text { Season } \\
\text { Winter } 2008\end{array}$} & \multicolumn{7}{|l|}{ Date } \\
\hline & Aug-29 & Aug-30 & Aug-31 & Sep-01 & Sep-02 & Sep-03 & \\
\hline \multirow[t]{2}{*}{$\mathrm{ET}^{*}$ interfluve (mm) } & 1.3 & 2.2 & & 0.9 & 1.7 & 1.3 & \\
\hline & $(0.337)$ & $(0.570)$ & & $(0.233)$ & $(0.440)$ & $(0.337)$ & \\
\hline \multirow[t]{2}{*}{$\mathrm{ET}^{*}$ wetland $(\mathrm{mm})$} & 2.3 & 2.9 & 3.5 & 2.5 & 3.4 & 2.8 & \\
\hline & $(0.023)$ & $(0.029)$ & $(0.035)$ & $(0.025)$ & $(0.034)$ & $(0.028)$ & \\
\hline Potential ET (mm) & 3.5 & 3.4 & 8.7 & 3.9 & 4.1 & 3.9 & \\
\hline Rain interfluve (mm) & 0 & 0 & 0 & 0 & 0 & 0 & \\
\hline Rain wetland (mm) & 0 & 0 & 0 & 0 & 0 & 0 & \\
\hline Discharge $(\mathrm{mm})$ & 0 & 0 & 0 & 0 & 0 & 0 & \\
\hline \multirow[t]{2}{*}{$\Delta \mathrm{S}(\mathrm{mm})$ interfluve } & -1.3 & -2.2 & & -0.9 & -1.7 & -1.3 & \\
\hline & $(-0.337)$ & $(-0.570)$ & & $(-0.233)$ & $(-0.440)$ & $(-0.337)$ & \\
\hline \multirow[t]{2}{*}{$\Delta \mathrm{S}(\mathrm{mm})$ wetland } & -2.3 & -2.9 & -3.5 & -2.5 & -3.4 & -2.8 & \\
\hline & $(-0.023)$ & $(-0.029)$ & $(-0.035)$ & $(-0.025)$ & $(-0.034)$ & $(-0.028)$ & \\
\hline Summer 2009 & Jan-28 & Jan-29 & Jan-30 & Jan-31 & Feb-01 & Feb-02 & Feb-03 \\
\hline \multirow[t]{2}{*}{$\mathrm{ET}^{*}$ interfluve $(\mathrm{mm})$} & 1.1 & 3.3 & 3.8 & & 1.7 & 4.9 & 4.8 \\
\hline & $(0.285)$ & $(0.855)$ & $(0.984)$ & & $(0.440)$ & $(1.269)$ & $(1.243)$ \\
\hline \multirow[t]{2}{*}{$\mathrm{ET}^{*}$ wetland $(\mathrm{mm})$} & 1.2 & 3.9 & 4.4 & 2.7 & 2.2 & 5.1 & 5.1 \\
\hline & $(0.012)$ & $(0.039)$ & $(0.044)$ & $(0.027)$ & $(0.022)$ & $(0.051)$ & $(0.051)$ \\
\hline Potential ET $(\mathrm{mm})$ & 1.3 & 3.6 & 3.9 & 1.9 & 2.2 & 5.2 & 5.6 \\
\hline \multirow[t]{2}{*}{ Rain interfluve (mm) } & 0.2 & 8.4 & 27.7 & 62.3 & 43.8 & 4.9 & 80.3 \\
\hline & $(0.052)$ & $(2.176)$ & $(7.174)$ & $(16.136)$ & (11.344) & $(1.269)$ & (20.798) \\
\hline \multirow[t]{2}{*}{ Rain wetland (mm) } & 0.2 & 8.4 & 27.7 & 62.3 & 43.8 & 4.9 & 80.3 \\
\hline & $(0.002)$ & $(0.084)$ & $(0.277)$ & $(0.623)$ & $(0.438)$ & $(0.049)$ & $(0.803)$ \\
\hline \multirow[t]{2}{*}{ Discharge $(\mathrm{mm})$} & 0.16 & 0.13 & 1.08 & 10.26 & 9.89 & 0.34 & 24.06 \\
\hline & $(0.043)$ & $(0.035)$ & $(0.291)$ & $(2.760)$ & $(2.660)$ & $(0.091)$ & $(6.472)$ \\
\hline \multirow[t]{2}{*}{$\Delta \mathrm{S}(\mathrm{mm})$ interfluve } & -0.74 & 5.23 & 24.94 & & 51.62 & 0.33 & 98.67 \\
\hline & $(-0.192)$ & $(-1.355)$ & $(6.459)$ & & (13.37) & $(0.085)$ & (25.556) \\
\hline \multirow[t]{2}{*}{$\Delta \mathrm{S}(\mathrm{mm})$ wetland } & -0.99 & 4.5 & 23.34 & 59.98 & 41.97 & -0.19 & 76.09 \\
\hline & $(-0.010)$ & $(0.045)$ & $(0.233)$ & $(0.600)$ & $(0.420)$ & $(-0.002)$ & $(0.761)$ \\
\hline
\end{tabular}

"Actual evapotranspiration quantified using Surface Layer Scintillometer, $\Delta$ S change in storage

Values in parentheses represent equivalent volumes $\left(\mathrm{Mm}^{3}\right)$

some striking insights and similarities may be gleaned from the literature. In the first instance, it is the underlying geology and concomitant hydrological processes that are particularly interesting. Dambo catchments typically contain permeable regolith on their interfluves contrasting with their typically lowconductivity valley bottom substrates (Bullock, 1992). This study reveals that the Craigieburn-Manalana wetland illustrates a permeable interfluve regime as a result of its dominantly granitic geology. There may be an initial dissimilarity with Bullock's (1992) description for valley bottom wetland material in the case of the Craigieburn-Manalana, in that it is dominated by coarse sands having a high hydraulic conductivity. However, it has been shown through hydrodynamic observation (Riddell et al., 2012) and geophysical surveys (Riddell et al., 2010) that there is indeed an increase in these valley bottom zones in the content of finer particles at depth, which act as a significant aquitard to groundwater flow. The water budget presented here takes this into account. The only major contrast with Bullock's (1992) description of dambos is that the Sand River wetland sediments are very deep (several metres) rather than shallow.

Whilst dambo systems have also been acknowledged to experience rapid water table rise, as noted, for example, by Balek and Perry (1973), the precise duration of this mechanism contrasts with the findings presented here, since in Balek and
Perry's study, at the Luano catchments in Zambia, the water table rise occurred over a period of approximately half the month of December 1969, and rose by less than $500 \mathrm{~mm}$. In the Craigieburn-Manalana wetland of the water table rise was over $500 \mathrm{~mm}$ in a matter of hours. Meanwhile, Acres et al. (1985) reported variations in water table response according to dambo soil type, in which predominantly sandy soils are saturated earlier in the wet season and are more liable to rapid water level rise and fluctuations than are predominantly clay soils. This confirms that a universal response is not apparent in all dambo systems. However, the superficially sandy material of the Craigieburn-Manalana wetland suggests that it conforms to the rapid water table rise mechanism. Although the precise mechanism for its occurrence at the CraigieburnManalana is here ascribed to be a result of a dual-porosity function of the interfluve-wetland interfacing soils, a model for similar mechanisms has been described for dambo catchments in Malawi by McFarlane (1992). The McFarlane model suggests rapid displacement of upwelling groundwater through the clay of the dambo floor via the underlying saprolite; this remains a possibility at the Craigieburn-Manalana as a contributory mechanism, which should be explored further. However, since there is undoubtedly a substantial clay lens at depth in the Craigieburn-Manalana, it is more likely that no 
discharge into the wetland occurs via the underlying regolith. A similar result was reported by McCartney and Neal (1999) for the Grasslands Research Station dambo in Zimbabwe. Rudimentary stable isotope analysis, of samples from $2000 \mathrm{~mm}$ deep piezometers (Fig. 5), suggests that there is a hydrological dis-connect between the shallow sub-surface of Craigieburn-Manalana wetland and regional groundwater, when compared to local groundwater borehole water samples. Based on qualitative interpretation of the samples proximity to one another on $a^{18} \mathrm{O} /{ }^{2} \mathrm{H}$ scatter plot, which does not provide conclusive evidence, there is a possibility of groundwater connectivity at $>2000 \mathrm{~mm}$ depth. Moreover, the McCartney and Neal (1999) model suggests that runoff within the dambo was derived from shallow sources and that when the water table dropped below the clay lens underlying the dambo discharge out of the dambo consequently ceased. Whilst the evidence of wetland hydrodynamic responses (Riddell et al., 2012) also shows that wetland through-flows are predominantly shallow in nature, the responses of the Manalana wetland may be similar given the observed short lag in water table decline following the cessation of streamflow, as shown in Fig. 6.

The catchment scale water budget components illustrated in Fig. 3 showed that the proportion of precipitation that is converted to runoff is generally $20-25 \%$ at the height of the rain season. The slight disparity seen in this study for the month of January 2009, in which the proportion of rainfall converted to runoff was lower than expected, may be a combination of reduced rainfall intensity for this period and problems associated with missing data due to equipment failure. These factors show similarity to Von der Heyden's (2004) assertion that dambo hydrology is driven by direct rainfall contributions as a function of rainfall intensity. Nevertheless, the hydrograph separation suggests that the dominant component of flow in this wetland system comes from event water, and this has interesting implications in terms of downstream processes and contrasts with the common perception that wetlands attenuate flows. However this assumption is based on a single hydrograph separation when the catchment was saturated. It is most likely that the ratio of event to pre-event water will be directly in relation to catchment antecedent soil moisture and the intensity of the precipitation event, as has been found in other dambos (e.g. McCartney et al., 1998). Unfortunate technical errors in streamflow sampling prevented further examination of these factors in this study.

Nevertheless, it certainly appears that these wetlands actually convey stormwater to downstream areas, most likely due to the emergence of a saturated area in the valley bottom, particularly later in the season, which prevents downward infiltration of stormwater into the wetland substrate. This transition, from an early season storage system when there is a soil moisture deficit (SMD) to one that becomes saturated and acts as a conduit of water after depletion of the SMD, has similarly been shown by McCartney (1998), and hence is a true similarity with the dambo hydrological model. This of course is influenced by the intensity of the rainfall event and soil hydraulic properties. Nevertheless, it does seem to suggest that these wetlands may increase a river's response to rainfall, as was shown in the majority of headwater wetland studies reviewed by Bullock and Acreman (2003). However, whilst this may be the case in the present situation in the Craigieburn-Manalana, it must also be remembered that certain factors, such as the network of drainage furrows in these wetlands, may also act to supply a significant proportion of the event water contributing to the wetland's discharge, since opportunities for stormwater detention have been significantly reduced in this system. Meanwhile, due to over 3 years of abandonment of these plots, emergent hydrophytic vegetation has re-colonised the area (personal nonquantified observation) and the hydraulic roughness portrayed by this vegetation will now be close to maximum and may go some way toward mitigating against the occurrence of these artificial channels.

It is also necessary to consider the dry season effects of wetlands on stream flows, in terms of the commonly-held perception of low flow augmentation. Bullock and Acreman (2003), in their review of wetland hydrology, suggested that the majority of studies implied both the greater net use of water by wetlands when compared with their contributing catchments as well as the effect of wetlands in reducing dry season flows downstream through evapotranspiration. The findings presented here would almost certainly adhere to both of these notions, as well as Von der Heyden's (2004) assertion that interfluve versus wetland vegetation characteristics are the determinants of ET losses from dambo catchments. A consistent reduction in the wetland storage was observed daily during the ET quantification campaign, attributed fully to the water use of hydrophytic vegetation, while at the same time there was no discharge occurring out of the wetland (at the surface at least and negligibly to groundwater). The findings presented here however merely reflect the water balance at the most headward end of the catchment, where distinct seasonality is observed in the streamflow response. As one moves downstream within the Craigieburn-Manalana catchment the wetland becomes perennial and free-flowing water is observed throughout the year. This perennial flow does however occur at a point where minor tributaries join the main stem of the wetland. Whether this lower part of the wetland intersects the regional water table or receives more sustained augmented low flows from some other hydrological processes in these tributaries remains to be characterised and it is recommended that this be done in the future. This is particularly necessary for upscaling and extrapolation of findings at the Craigieburn-Manalana wetland to the broader headwaters of the Sand River catchment.

\section{Conclusion}

This paper has summarised the findings of hydrological process definition in the context of the technical rehabilitation of a small headwater wetland, as well as current understanding of headwater wetland hydrology, namely, dambo systems, in southern Africa. For the most part, the Sand River wetlands show conformity with processes previously determined in other dambo systems, and the findings of this study certainly lend support to recent suggestions that headwater wetlands do not necessarily attenuate floodwater and augment base flows.

\section{Acknowledgements}

This research was funded by the South African Water Research Commission (WRC). The author acknowledges the kind contributions of Mr Ronny Maaboi, Mr Rex Mothlabini, and Mr Difference Thibela in fieldwork assistance. Logistical and administrative support was provided by the Association for Water and Rural Development (AWARD). Mr Cobus Pretorius is thanked for technical assistance. The authors also acknowledge the valuable contributions from anonymous reviewers on early versions of this manuscript. 


\section{References}

ACRES BD, RAINS AB, KING RB, LAWTON RM, MITCHELL AJB and RACKMAN LJ (1985) African dambos: their distribution,characteristics and use. Zeitschrift für Geomorphologie Supplementbande 52 62-83.

ALLEN RG, PEREIRA LS, RAES D and SMITH M (1998) Crop evapotranspiration - Guidelines for computing crop water requirements. FAO Irrigation and Drainage Paper 56. FAO (Food and Agriculture Organization of the United Nations), Rome.

BALEK J and PERRY JE (1972) Hydrology of seasonally inundated African headwater swamps. J. Hydrol. 19 227-249.

BOUWER H and RICE RC (1976) A slug test for determining hydraulic conductivity of unconfined aquifers with completely or partially penetrating wells. Water Resour. Res. 12 (3) 423-428.

BULLOCK A (1992) Dambo hydrology in southern Africa - review and reassessment. J. Hydrol. 134 373-396.

BULLOCK A and ACREMAN M (2003) The role of wetlands in the hydrological cycle. Hydrol. Earth Syst. Sci. 7 (3) 358-389.

ELLERY WN, GRENFELL M, GRENFELL S, KOTZE DC, McCARTHY TS, TOOTH S, GRUNDLING PL, BECKEDAHL H, LE MAITRE D and RAMSAY L (2008) WET-Origins: Controls on the distribution and dynamics of wetlands in South Africa WRC Report No. TT 334/08. Water Research Commission, Pretoria. $100 \mathrm{pp}$.

FAO (1998) World Reference Base for Soil Resources. Food and Agriculture Organization of the United Nations (FAO), International Society of Soil Science (ISSS-AISS-IBG), International Soil Reference Group. URL: http://www.fao.org/ docrep/W8594E/W8594E00.htm (Accessed August 2011).

GRENFELL MC, ELLERY WN and PRESTON-WHYTE RA (2005) Wetlands as early warning (eco)systems for water resource management. Water SA 31 (4) 465-471.

McCARTNEY MP (2000) The water budget of a headwater catchment containing a dambo. Phys. Chem. Earth (B) 25 (7-8) 611-616.

McCARTNEY MP (1998) The hydrology of a headwater catchment containing a dambo. PhD thesis, University of Reading, Department of Soil Science. 266 pp.

McCARTNEY MP, NEAL C and NEAL M (1998) Use of deuterium to understand runoff generation in a headwater catchment containing a dambo. Hydrol. Earth Syst. Sci. 2 (1) 65-76.

McCARTNEY MP and NEAL C (1999) Water flow pathways and the water balance within a headwater catchment containing a dambo: inferences drawn from hydrochemical investigations. Hydrol. Earth Syst. Sci. 3 (4) 581-591.

McFARLANE MJ (1992) Groundwater movement and water chemistry associated with weathering profiles of the African surface in parts of Malawi. Geol. Soc. Spec. Publ. 66 101-129.

MUCINA L and RUTHERFORD MC (2006) The Vegetation of South Africa, Lesotho and Swaziland. South African National Biodiversity Institute, Pretoria. 807 pp.

POLLARD S, KOTZE D, ELLERY W, COUSINS T, MONARENG J, KING K and JEWITT G (2005) Linking water and livelihoods. The development of an integrated wetland rehabilitation plan in the communal areas of the Sand River Catchment as a test case. Association for Water and Rural Development, South Africa. URL: http://www.award.org.za/File uploads/File/WL\%20Phase $\% 20$ I\%20final\%20report \%202005-2.pdf (Accessed January 2012).

POLLARD S and DU TOIT D (2011) The Shared Rivers Initiative Phase 1. Towards the sustainability of freshwater systems in South Africa: An exploration of factors that enable or constrain meeting the Ecological Reserve within the context of Integrated Water Resources Management in the catchments of the lowveld. WRC Report No. TT 477/10, Water Research Commission, Pretoria. 194 pp.

POLLARD S, MALLORY S, RIDDELL E and SAWUNYAMA T (2012) Towards improving the assessment and implementation of the Reserve: Real-time assessment and implementation of the Ecological Reserve. WRC Report No KV 282/11, Water Research Commission, Pretoria.

RIDDELL ES, LORENTZ SA and KOTZE DC (2010) A geophysical analysis of hydro-geomorphic controls within a headwater wetland in a granitic landscape, through ERI and IP. Hydrol. Earth Syst. Sci. 14 1697-1713

RIDDELL ES (2011) Characterisation of the hydrological processes and responses to rehabilitation of a headwater wetland of the Sand River, South Africa. PhD thesis, University of KwaZulu-Natal, Pietermaritzburg, South Africa. 351 pp. URL: http://researchspace. ukzn.ac.za/jspui/handle/10413/3636.

RIDDELL ES, LORENTZ SA and KOTZE DC (2012) The hydrodynamic response of a semi-arid headwater wetland to technical rehabilitation interventions. Water $S A 38$ (1) 55-66.

SAVAGE M (2009) Estimation of evaporation using a dual-beam surface layer scintillometer and component energy balance measurements. Agric. For. Meteorol. 149 510-517.

SCHULZE RE (1995) Hydrology and Agrohydrology: A text to accompany the ACRU 3.00 Agrohydrological Modelling System. WRC Report No. TT 69/95. Water Research Commission, Pretoria.

SOIL CLASSIFICATION WORKING GROUP (1991) Soil classification a taxonomic system for South Africa. Memoirs on the Agricultural Natural Resources of South Africa No. 15. SIRI, D.A.T.S., Pretoria.

TOOTH S and McCARTHY TS (2007) Wetlands in drylands: geomorphological and sedimentological characteristics, with emphasis on examples from Southern Africa. Prog. Phys. Geogr. 31 (1) 3-41.

UHLENBROOK S and HOEG S (2003) Quantifying uncertainties in tracer-based hydrograph separations: a case study for two-, threeand five-component hydrograph separations in a mountainous catchment. Hydrol. Processes 17 431-453.

US DEPARTMENT OF THE INTERIOR, BUREAU OF RECLAMATION (2001) Water Measurement Manual Water Resources Research Laboratory. URL: http://www.usbr.gov/pmts/ hydraulics lab/pubs/wmm (Accessed January 2012).

VON DER HEYDEN CJ and NEW MG (2003) The role of a dambo in the hydrology of a catchment and the river network downstream. Hydrol. Earth Syst. Sci. 7 (3) 339-357.

VON DER HEYDEN CJ (2004) The hydrology and hydrogeology of dambos: a review. Prog. Phys. Geogr. 28 (4) 544-564. 